\title{
Lower esophageal sphincter-preserving laparoscopy-assisted proximal gastrectomy in patients with early gastric cancer: a method for the prevention of reflux esophagitis
}

\author{
Dong Jin Kim $\cdot$ Jun Hyun Lee $\cdot$ Wook Kim
}

Received: 6 April 2012/ Accepted: 23 September 2012/Published online: 13 October 2012

(c) The International Gastric Cancer Association and The Japanese Gastric Cancer Association 2012

\begin{abstract}
Although laparoscopy-assisted proximal gastrectomy (LAPG) with esophagogastrostomy for early gastric cancer (EGC) is technically feasible and oncologically safe, it has not been popularized because of the frequent occurrence of reflux esophagitis associated with loss of the lower esophageal sphincter (LES). Herein, we present surgical outcomes in patients with LES-preserving LAPG (LES-p LAPG), which may contribute to protecting against postoperative gastroesophageal reflux or stricture in the treatment of proximal EGC. From November 2009 to May 2010, LES-p LAPG was performed in nine patients with clinical EGC, located at the proximal one-third of the stomach with the upper margin of the tumor $3-4 \mathrm{~cm}$ from the esophagogastric junction. After the resection of the proximal stomach with $\mathrm{D} 1+\beta$ lymph node dissection, gastrogastrostomy was performed using a $25-\mathrm{mm}$ circular stapler through a mini-laparotomy wound at the epigastrium. The median operating time was $137.5 \mathrm{~min}$ (range 120-180). The median number of retrieved lymph nodes and length of the proximal resection margin were 27 (range 7-49) and $2.4 \mathrm{~cm}$ (range 0.7-5), respectively. The postoperative complications included one gastrogastrostomy stricture and one case of leakage, which were managed by endoscopic balloon dilation and conservative treatment, respectively. None of the patients suffered from symptoms of reflux esophagitis during the follow-up period (median 15 months; range 8-28 months). This technique of LES-p LAPG for the treatment of proximal EGC could be a simple, safe, and useful technique to prevent esophageal reflux or stricture. This technique requires prospective validation.
\end{abstract}

D. J. Kim · J. H. Lee · W. Kim $(\square)$

Department of Surgery, Yeouido St. Mary's Hospital,

College of Medicine, The Catholic University of Korea,

62 Yeouido-dong, Yeongdeungpo-gu, Seoul 150-713, Korea

e-mail:kimwook@catholic.ac.kr
Keywords Laparoscopic gastrectomy $\cdot$ Early gastric cancer · Proximal gastric cancer

\section{Introduction}

While the incidence of early gastric cancer (EGC) in Korea has been rapidly increasing, from $32.8 \%$ (1999) to $57.7 \%$ (2009), there was only a small change, from 12.5 to $13.4 \%$, in the proportion of proximal gastric cancer cases according to the nationwide survey performed by the Korean Gastric Cancer Association [1, 2]. Total gastrectomy has been performed as a standard procedure with Roux-en-Y reconstruction for treating upper gastric cancer regardless of the stage, but it has critical limitations, including leaving no food reservoir and bypassing the duodenum, resulting in nutritional abnormality.

To avoid these problems, many surgeons perform proximal gastrectomy in selective patients with EGC [3-7]. However, reflux esophagitis and stricture have always been troublesome issues following proximal gastrectomy. Recently, we designed a new procedure for laparoscopicassisted proximal gastrectomy (LAPG); in this procedure, we preserved the lower esophageal sphincter (LES) for the prevention of gastroesophageal reflux. This report shows the short-term surgical results.

\section{Patients and technique}

Indications for surgery

Patients with histologically confirmed adenocarcinoma with the clinical tumor depth confined to EGC and its upper 
margin located more than $3-4 \mathrm{~cm}$ from the esophagogastric junction (EGJ) were included between November 2009 and May 2010. All patients were preoperatively diagnosed with EGC without any suspicious lesion suggesting lymph node metastasis using preoperative evaluation modalities including the gastrofiberscope (GFS), computerized tomography (CT) scan and endoscopic ultrasound (EUS). Patients with preoperative reflux symptoms were excluded from this study.

\section{Operative procedures}

The regional lymph nodes and other pathological data were described according to the Japanese Classification of Gastric Carcinoma (third English edition) [8]. Under general anesthesia, the patient was placed in a $15^{\circ}-20^{\circ}$ reverse Trendelenburg position. An initial 10-mm trocar for use as a flexible electro-laparoscope was inserted through the subumbilical area using the Hassan technique. After establishing a pneumoperitoneum with carbon dioxide $\left(\mathrm{CO}_{2}\right)$, the operator stood on the right side of the patient, and the pneumoperitoneum was maintained at $12 \mathrm{mmHg}$. During the surgery, five trocars were placed as illustrated in Fig. 1. The distal resection margin was marked with a marking pencil, and redundancy was checked to verify the existence of a tension-free anastomosis. During the operations, this mark served as the reference point for determining the transection line of the stomach. The left-side greater omentum, gastrosplenic (including short gastric vessels) and gastrophrenic ligament were divided with ultrasonic shears [Laparoscopic Coagulation Shears $\left(\mathrm{LCS}^{\circledR}\right)$; Ethicon Endo-Surgery, Cincinnati, OH, USA). Laparoscopically, the spleen was preserved, and the group 1 lymph nodes along the greater and lesser curvatures of the stomach (the right pericardial lymph nodes, left pericardial lymph nodes, lymph nodes along the lesser curvature, lymph nodes along the short gastric vessels, and lymph nodes along the left gastroepiploic vessels) were dissected. In addition, the lymph nodes along the left gastric artery (no. 7), common hepatic artery (no. 8a), celiac artery (no. 9) and splenic artery (no. $11 \mathrm{p}, \mathrm{d}$ ) were dissected to complete the $\mathrm{D} 1+\beta$ dissection.

After full mobilization of the abdominal esophagus with division of the vagus nerves, distal resection was performed with an Endo-GIA (US Surgical, Norwalk, CT, USA). A 4-cm-long midline incision was made by extension of the 10-mm trocar site at the epigastrium, and the laparotomy wound was protected with wound protector (Alexis ${ }^{\circledR}$, Applied Medical, Rancho Santa Margarita, CA, USA). After full mobilization of the proximal part of the divided stomach through the laparotomy wound, an autopurse-string suture device (US Surgical, Norwalk, CT, USA) was applied at the line located $1.5-2.5 \mathrm{~cm}$ distal

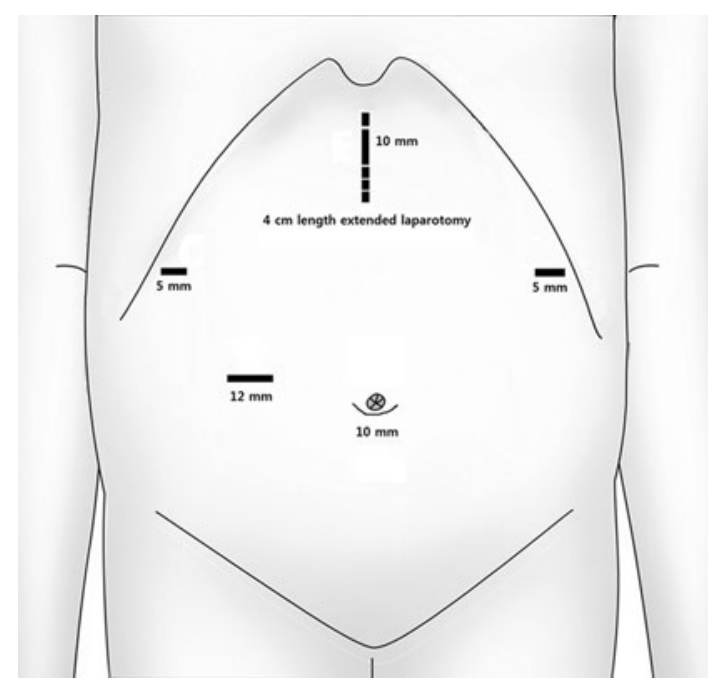

Fig. 1 Placement of the trocars

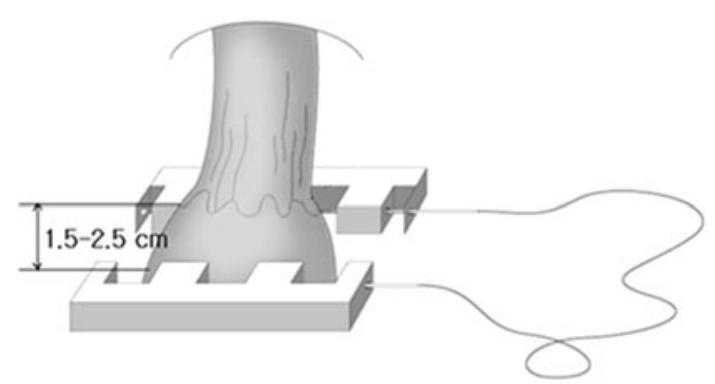

Fig. 2 Application of an auto-purse-string suture device before resection of the stomach (this figure is reproduced with permission from the Korean Surgical Society [17])

from the LES on the lesser curvature side by pulling the greater curvature side of the angle of His downward; the proximal part of the stomach was then divided (Fig. 2). The surgical margins were confirmed to be negative for cancer cells by frozen section. The greater curvature side of the staple line on the remnant distal stomach was opened to a length of $3 \mathrm{~cm}$, and anastomosis was performed using a 25-mm end-to-end anastomosis (EEA) stapler (US Surgical, Norwalk, CT, USA) (Fig. 3). After the entry hole had been closed with a linear stapler, the reconstruction was completed (Fig. 4). Pyloroplasty was added in a HeinekeMikulicz fashion in all cases.

\section{Results}

Detailed information on the nine patients is described in Table 1. There were six male patients and three female patients. The median age was 58 years (range 51-76). Two patients were indicated for surgery after endoscopic submucosal dissection because of margin involvement. Postoperative pathological evaluation revealed a T1a lesion in 


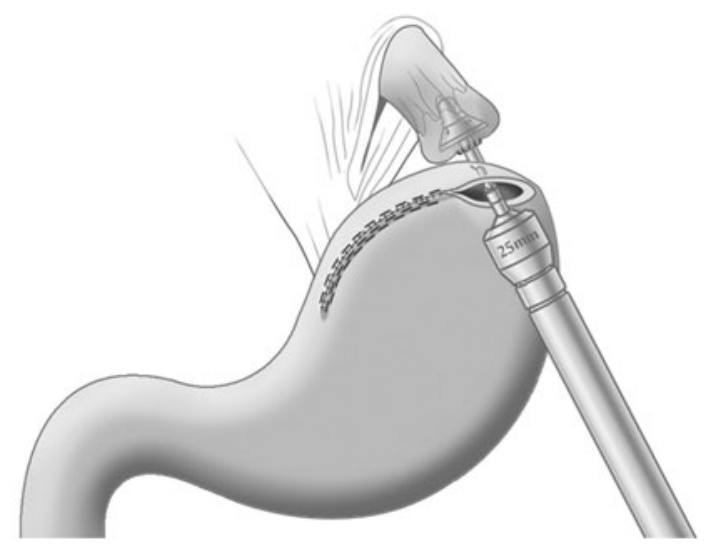

Fig. 3 Anastomosis is ready after an anvil has been inserted into the remnant cardia and a $25-\mathrm{mm}$ circular stapler introduced through the distal remnant stomach
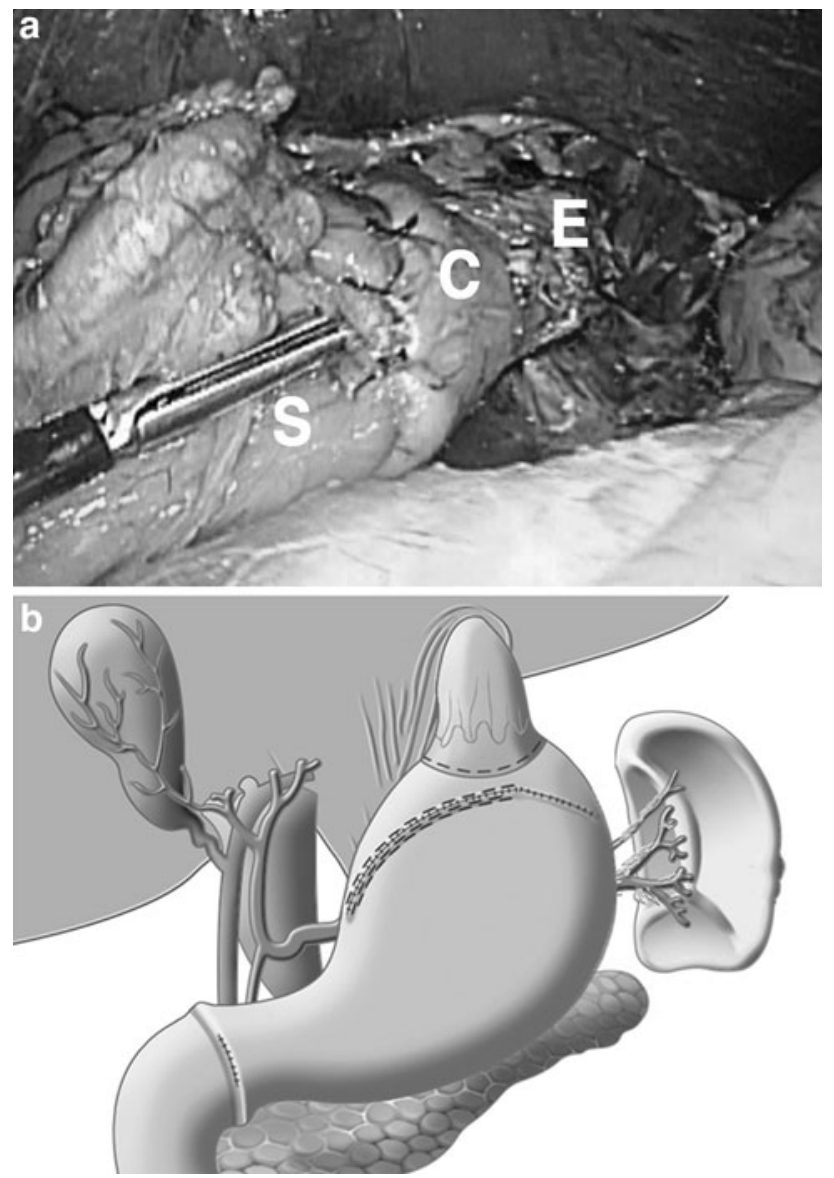

Fig. 4 a Laparoscopic view of the completed anastomosis: $E$ esophagus, $C$ remnant cardia, $S$ remnant distal stomach. b Illustration of the completed anastomosis

three patients, a T1b lesion in four patients and a T2 lesion in two patients. Median tumor size was $1.8 \mathrm{~cm}$ (range $0.5-5.3)$; the median proximal and distal resection margins were $2.4 \mathrm{~cm}$ (range $0.7-5$ ) and $5.1 \mathrm{~cm}$ (range 2.8-7), respectively. The median number of retrieved lymph nodes was 27 (range 7-49), and there were no metastatic nodes.

The median operation time was $137.5 \mathrm{~min}$ (range 120-180). All patients started liquid diets within 4 days after the operation (median 3 days). Median length of stay was 8 days (range 7-11). None of the patients had to stop eating temporarily because of reflux, stricture or gastric stasis during the hospital stay.

One anastomotic stricture ( 3 months after surgery) and one anastomotic leakage ( 2 weeks after surgery) developed postoperatively and were managed by balloon dilatation and conservative management, respectively. GFS findings, performed 6 months after the operation, revealed an intact anastomosis line and EGJ (Fig. 5). None of the patients suffered from symptoms related to reflux such as regurgitation or heart burn, and none of the patients were treated with a proton pump inhibitor postoperatively. There were no cases of mortality or recurrence during the 15-month median follow-up period (range 8-28 months).

\section{Discussion}

Recently, the prevalence of EGC in the middle or upper third of the stomach has been increasing $[9,10]$. Accordingly, there has been much more interest in treatment strategies for EGC in upper gastric cancer. Also technical advances have made it possible to treat gastric cancer patients with less invasive and traumatic methods such as laparoscopic surgery or endoscopic procedures. While Hirai et al. [5] insisted the EMR of the gastric cardia is at high risk of perforation or hemorrhage because of the thin stomach wall in the gastric cardia, unclear tumor border and frequent invasion of the submucosal layer, there are many reports regarding the feasibility and safety of laparoscopy-assisted proximal gastrectomy [6, 11-14]. However, there are still some problems with proximal gastrectomy related to postoperative symptoms such as reflux esophagitis and anastomotic stenosis [7].

There are two main points that differentiate our operational technique from the laparoscopic approach. One is full preservation of the LES, and the other is creation of an anastomosis with gastrogastrostomy, similar to an inverted version of the pylorus-preserving gastrectomy (PPG). There is no definitely named vessel or nerve supplying the LES area. This allows for complete dissection of LN nos. 1, 2 and division of the vagus nerves without any compromise of the blood supply or nerve innervations into the LES area. When we preserve the LES and EGJ, there is no reason to worry about preserving the nerve and vessels as in PPG [15].

In our study, although there were two cases showing LA classification A, no patient was suffered from reflux 
Table 1 Detailed information on the nine patients who underwent LES-p LAPG

\begin{tabular}{|c|c|c|c|c|c|c|c|c|c|c|c|c|}
\hline No. & Age & Sex & $\begin{array}{l}\text { Stage } \\
\text { (UICC } \\
7 \text { th) }\end{array}$ & $\begin{array}{l}\text { Tumor } \\
\text { size }(\mathrm{cm})\end{array}$ & $\begin{array}{l}\text { Number of } \\
\text { Retrieved } \\
\text { LN }\end{array}$ & $\begin{array}{l}\text { PRM } \\
(\mathrm{cm})\end{array}$ & $\begin{array}{l}\text { DRM } \\
(\mathrm{cm})\end{array}$ & $\begin{array}{l}\text { Op. } \\
\text { time } \\
\text { (min) }\end{array}$ & $\begin{array}{l}\text { Resume } \\
\text { LD } \\
\text { (POD) }\end{array}$ & $\begin{array}{l}\text { LOS } \\
\text { (days) }\end{array}$ & Morbidity & Remarks \\
\hline 1 & 51 & Male & T1aN0M0 & $1.2 \times 1$ & 7 & 1.5 & 4 & 140 & 3 & 8 & None & \\
\hline 2 & 76 & Male & T1aN0M0 & $0.5 \times 0.5$ & 10 & 1.7 & 5.5 & 135 & 4 & 8 & Stricture & \\
\hline 3 & 58 & Female & T1bN0M0 & $2.3 \times 1.5$ & 37 & 2.5 & 2.8 & 132 & 3 & 7 & None & \\
\hline 4 & 55 & Male & T1bN0M0 & $1.6 \times 1.2$ & 32 & 2.4 & 5.5 & 120 & 4 & 11 & None & $\begin{array}{l}\text { Synchronous rt. } \\
\text { colon cancer }\end{array}$ \\
\hline 5 & 58 & Female & T1aN0M0 & $5.3 \times 4.5$ & 26 & 3.8 & 4.5 & 120 & 3 & 7 & None & GB stone \\
\hline 6 & 65 & Female & T1bN0M0 & $1.8 \times 1.5$ & 20 & 3 & 7 & 180 & 4 & 8 & None & \\
\hline 7 & 60 & Male & T1bN0M0 & $1.7 \times 1.5$ & 27 & 5 & 6.6 & 150 & 3 & 8 & None & \\
\hline 8 & 56 & Male & T2N0M0 & $1.5 \times 2.5$ & 49 & 0.7 & 5.1 & 175 & 3 & 9 & None & \\
\hline 9 & 67 & Male & T2N0M0 & $2.2 \times 4.3$ & 21 & 2.2 & 4.3 & 140 & 3 & 8 & Leakage & \\
\hline
\end{tabular}

$P R M$ proximal resection margin, $D R M$ distal resection margin, $L D$ liquid diet, $P O D$ postoperative day, $L O S$ length of stay

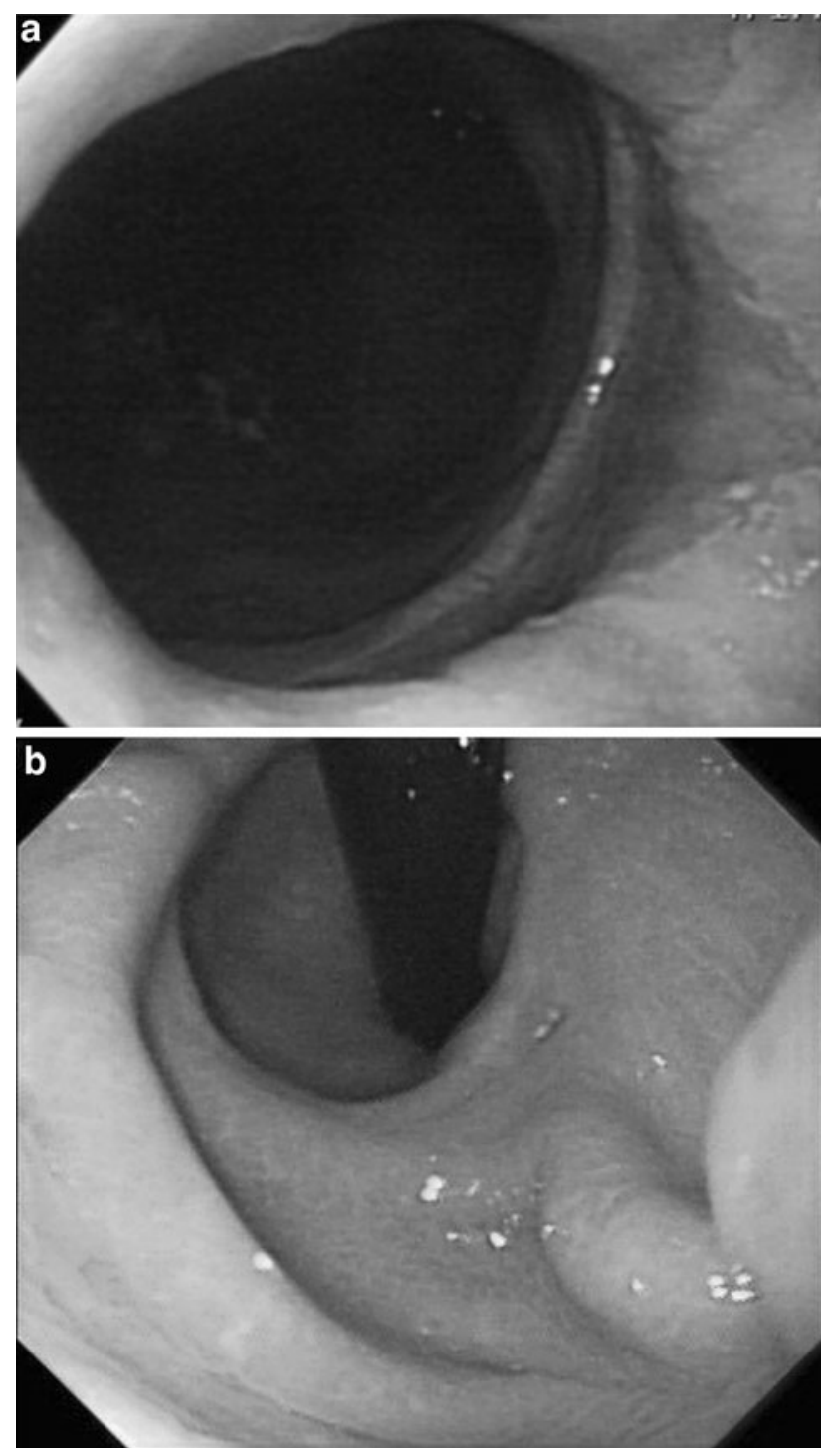

Fig. 5 Postoperative endoscopic findings. a Intact $z$-line and anastomosis site; $\mathbf{b}$ J-turn view of the gastrofiberscope symptoms such as regurgitation or heartburn. In terms of reflux esophagitis, we focused on the patient's subjective symptoms rather than endoscopic findings. While Sakuramoto et al. [6] focused on endoscopic findings regarding reflux esophagitis after proximal gastrectomy, many reports [3, 4, 14, 16] focused on symptoms rather than endoscopic findings. Although those reports did not describe the exact reason why they focused on patients' symptoms, it is true that the existence of reflux symptoms is an important criterion in the diagnosis of gastroesophageal reflux disease and prescription of PPI.

In terms of anastomotic stricture, some reports showed favorable results with jejunal interposition [3] or gastric tube formation [14]. However, jejunal interposition is technically difficult and requires many anastomoses. An et al. [7] and Aihara et al. [14] reported anastomotic stricture rates of 38.2 and $35 \%$ for proximal gastrectomy followed by gastric tube reconstruction, respectively. However, our previous study showed superior results with anastomotic stenosis [17]. Pierie et al. [18] considered compromised vascularity due to the creation of a gastric tube as one of the contributing factors, and we considered the relatively small diameter of the esophagus to be another reason. With our method, we can preserve vascularity, and the relatively large diameter of the stump is used to create anastomosis. We already have experience using a $25-\mathrm{mm}$ EEA stapler for making an anastomosis between the remnant cardia and jejunal pouch [17]. For this reason, we made an anastomosis with a 25-mm EEA stapler, which is usually used for esophagojejunostomy. However, there were no difficulties in making the anastomosis, and it was the proper size for gastrogastrostomy anastomosis. Although there were two anastomosis-related complications, we considered that these complications are not directly related to the size of the circular stapler. 
In conclusion, LES-p LAPG for the treatment of proximal EGC could be a simple, safe, and useful technique to prevent esophageal reflux or stricture. Its clinical usefulness requires prospective validation.

Acknowledgments This study has no related financial support.

\section{References}

1. The Information Committee of the Korean Gastric Cancer Association. 2004 Nationwide gastric cancer report in Korea. J Korean Gastric Cancer Assoc. 2007;7:47-54.

2. Jeong O, Park YK. Clinicopathological features and surgical treatment of gastric cancer in South Korea: the results of 2009 nationwide survey on surgically treated gastric cancer patients. J Gastric Cancer. 2011;11:69-77.

3. Katai H, Sano T, Fukagawa T, Shinohara H, Sasako M. Prospective study of proximal gastrectomy for early gastric cancer in the upper third of the stomach. Br J Surg. 2003;90:850-3.

4. Shiraishi N, Adachi Y, Kitano S, Kakisako K, Inomata M, Yasuda K. Clinical outcome of proximal versus total gastrectomy for proximal gastric cancer. World J Surg. 2002;26:1150-4.

5. Hirai T, Matsumoto H, Iki K, Hirabayashi Y, Kawabe Y, Ikeda $\mathrm{M}$, et al. Lower esophageal sphincter- and vagus-preserving proximal partial gastrectomy for early cancer of the gastric cardia. Surg Today. 2006;36:874-8.

6. Sakuramoto S, Yamashita K, Kikuchi S, Futawatari N, Katada N, Moriya $\mathrm{H}$, et al. Clinical experience of laparoscopy-assisted proximal gastrectomy with Toupet-like partial fundoplication in early gastric cancer for preventing reflux esophagitis. J Am Coll Surg. 2009;209:344-51.

7. An JY, Youn HG, Choi MG, Noh JH, Sohn TS, Kim S. The difficult choice between total and proximal gastrectomy in proximal early gastric cancer. Am J Surg. 2008;196:587-91.
8. Japanese Gastric Cancer A. Japanese Classification of Gastric Carcinoma - 2nd English Edition. Gastric Cancer 1998;1:10-24.

9. Salvon-Harman JC, Cady B, Nikulasson S, Khettry U, Stone MD, Lavin P. Shifting proportions of gastric adenocarcinomas. Arch Surg. 1994;129:381-8 (discussion 388-9).

10. Park CH, Song KY, Kim SN. Treatment results for gastric cancer surgery: 12 years' experience at a single institute in Korea. Eur J Surg Oncol. 2008;34:36-41.

11. Kitano S, Adachi Y, Shiraishi N, Suematsu T, Bando T. Laparoscopic-assisted proximal gastrectomy for early gastric carcinomas. Surg Today. 1999;29:389-91.

12. Uyama I, Sugioka A, Matsui H, Fujita J, Komori Y, Hatakawa Y, et al. Laparoscopic side-to-side esophagogastrostomy using a linear stapler after proximal gastrectomy. Gastric Cancer. 2001;4: 98-102.

13. Tonouchi H, Mohri Y, Tanaka K, Kobayashi M, Kusunoki M. Hemidouble stapling for esophagogastrostomy during laparoscopically assisted proximal gastrectomy. Surg Laparosc Endosc Percutan Tech. 2006;16:242-4.

14. Aihara R, Mochiki E, Ohno T, Yanai M, Toyomasu Y, Ogata K, et al. Laparoscopy-assisted proximal gastrectomy with gastric tube reconstruction for early gastric cancer. Surg Endosc. 2010; 24:2343-8.

15. Jiang X, Hiki N, Nunobe S, Fukunaga T, Kumagai K, Nohara K, et al. Long-term outcome and survival with laparoscopy-assisted pylorus-preserving gastrectomy for early gastric cancer. Surg Endosc. 2011;25:1182-6.

16. Kim JH, Park SS, Kim J, Boo YJ, Kim SJ, Mok YJ, et al. Surgical outcomes for gastric cancer in the upper third of the stomach. World J Surg. 2006;30:1870-6 (discussion 7-8).

17. Kim DJ, Hur H, Jeon HM, Kim W. Near-total gastrectomy preserving the lower esophageal sphincter followed by jejunal pouch interposition as a treatment for upper gastric cancer. J Korean Surg Soc. 2010;78:290-7.

18. Pierie JP, de Graaf PW, Poen H, van der Tweel I, Obertop H. Incidence and management of benign anastomotic stricture after cervical oesophagogastrostomy. Br J Surg. 1993;80:471-4. 